\title{
Differential regulation of stiffness, topography, and dimension of substrates in rat mesenchymal stem cells
}

\author{
Zhan Li, Yuanwei Gong, Shujin Sun**, Yu Du, Dongyuan Lü, Xiaofeng Liu, Mian Long* \\ Center of Biomechanics and Bioengineering and Key Laboratory of Microgravity (National Microgravity Laboratory), Institute of Mechanics, Chinese
} Academy of Sciences, Beijing 100190, China

\section{A R T I C L E I N F O}

\section{Article history:}

Received 20 May 2013

Accepted 26 June 2013

Available online 14 July 2013

\section{Keywords:}

Stiffness

Topography

Dimension

Stem cell

Proliferation

Differentiation

\begin{abstract}
A B S T R A C T
The physiological microenvironment of the stem cell niche, including the three factors of stiffness, topography, and dimension, is crucial to stem cell proliferation and differentiation. Although a growing body of evidence is present to elucidate the importance of these factors individually, the interaction of the biophysical parameters of the factors remains insufficiently characterized, particularly for stem cells. To address this issue fully, we applied a micro-fabricated polyacrylamide hydrogel substrate with two elasticities, two topographies, and three dimensions to systematically test proliferation, morphology and spreading, differentiation, and cytoskeletal re-organization of rat bone marrow mesenchymal stem cells (rBMSCs) on twelve cases. An isolated but not combinatory impact of the factors was found regarding the specific functions. Substrate stiffness or dimension is predominant in regulating cell proliferation by fostering cell growth on stiff, unevenly dimensioned substrate. Topography is a key factor for manipulating cell morphology and spreading via the formation of a large spherical shape in a pillar substrate but not in a grooved substrate. Although stiffness leads to osteogenic or neuronal differentiation of rBMSCs on a stiff or soft substrate, respectively, topography or dimension also plays a lesser role in directing cell differentiation. Neither an isolated effect nor a combinatory effect was found for actin or tubulin expression, whereas a seemingly combinatory effect of topography and dimension was found in manipulating vimentin expression. These results further the understandings of stem cell proliferation, morphology, and differentiation in a physiologically mimicking microenvironment.
\end{abstract}

(c) 2013 Elsevier Ltd. All rights reserved.

\section{Introduction}

The stem cell niche is crucial to stem cell self-renewal and multilineage differentiation under a physiological microenvironment [1]. In previous studies, the niche was used to define a multi-typed subpopulation of neighboring cells to preserve the pluripotency of stem cells. Different types of niche cells provide a distinct supporting environment, as observed in osteoblast-like cells to mesenchymal stem cells (MSCs) or hematopoietic stem cells (HSCs) $[2,3]$ or endothelial cells to neural stem cells (NSCs) [4-7]. The niche also provides the physical anchorage for stem cells via adhesive molecules such as integrins or cadherins in the surrounding environment. Exogenous signaling molecules such as Wnt or bone morphogenetic protein (BMP) derived from the niche can regulate the fate and amount of stem cells [8-12]. Currently, the stem cell

\footnotetext{
* Corresponding author. Fax: +86 1082544131.

** Corresponding author. Fax: +86 1082543795

E-mail addresses: sunshj@imech.ac.cn (S. Sun), mlong@imech.ac.cn (M. Long).
}

niche is expanded to define the surrounding microenvironment of both supporting cells and the extracellular matrix (ECM) at a specific tissue site.

Recently, the biomechanical or biophysical microenvironment has attracted much attention to elucidate the functions of the ECM niche. Substrate stiffness has been found to regulate the multilineage differentiation of stem cells. MSCs can differentiate into osteoblasts, myoblasts, or neurons on stiff, relatively stiff, or soft polyacrylamide (PA) hydrogel, respectively [5,13]. Independently of or associated with biochemical stimuli, such stiffness-based regulation of stem cells activates the downstream mechanotransduction of MSCs by manipulating the focal adhesive complex and cytoskeletal organization [14,15], activating integrin-based signaling pathways [14-17], regulating stem cell secretion of matrix metalloproteinases and intercellular adhesive molecules [18], and, finally, determining the fate of stem cell differentiation [5,19-23]. By attempting to mimic or even replicate in vivo ECM stiffness on a two-dimensional (2D) or planar substrate, these in vitro studies have opened a window from a biomechanical or biophysical viewpoint for lineage differentiation of various types of stem cells. 
A body of evidence has also been found for mechanically regulated growth, spreading, and differentiation of stem cells placed on a three-dimensional (3D), topographical substrate because the in vivo niche usually manifests a $3 \mathrm{D}$ structure at different tissue sites. Multiple topographies, including grooved, grid, pillar, or hexagonally pitched substrates have been employed in in vitro studies to mimic the physiological niche. Poly-dimethylsiloxane (PDMS) substrate with topographically patterned ridges and grooves could promote osteogenic differentiation in hMSCs [24]. Microwells on polyethylene glycol (PEG) could also modulate differentiation of adipocytes or neurons in MSCs [25]. Meanwhile, grid or lattice topography on PA and PDMS substrates are associated with murine MSC morphology and adhesion [26,27], whereas pillar and hexagonal substrates are related with drug or gene delivery to hMSCs [28,29]. Recently, 2176 randomized libraries of surface topographies designed from mathematical algorithms were applied to map the interplay between cells and surface topography and to unravel the unique, formerly unknown, topographies that can induce MSC proliferation or osteogenic differentiation [30]. Similarly, the effectiveness of topography variation was quantified systematically in several micro-engineered substrates [27]. It seems that the impact of substrate topography manifests the diversity for the directed differentiation of MSCs.

Moreover, the dimension of the topographical substrate is also crucial for stem cell self-renewal and lineage differentiation, proliferation, spreading, and cytoskeleton re-organization. Dimension dependence was observed for the differentiation of human or rat MSCs placed on pitched PDMS substrate or $\mathrm{TiO}_{2}$ nanotubes [24,31]. Additionally, similar to the effect of substrate stiffness, such dimension-induced differentiation can be associated with chemically induced differentiation, as found in the observations that MSCs revealed combinatory effects of topography and chemical cues (osteoinductive medium) on 400-nm pitch [24] and combinatory effects of nanoscale topography and growth factors (BMP-2) on 15- or 100-nm nanotubes [31]. Furthermore, dimension-specific proliferation [24,32] and adhesion [33] of human or rat MSCs have also been observed. Thus, dimension specificity also plays a role in manipulating lineage differentiation and other biological behaviors of MSCs.

The tissue-specific 3D niche regulates stem cell fate commitment. To date, little is known regarding the combined impacts of substrate stiffness, topography, and dimension on regulating the functions of stem cells, although each of the three factors has been well-studied, and the integration of any two of them has begun to be known. In the present study, the stiffness, topography, and dimension of the substrate onto which rat bone marrow mesenchymal stem cells (rBMSCs) were placed were systematically varied to quantify cell proliferation, morphology, differentiation, and cytoskeletal remodeling. The differential regulation of stem cell functions was discussed.

\section{Materials and methods}

\subsection{Fabrication and identification of biopolymer substrates}

PA hydrogel was used to construct the topographical surface via a soft-contact lithography technique [34]. Briefly, $40 \%$ acrylamide and $2 \%$ bis-acrylamide were mixed with water in a volume of $10 \mathrm{ml}$ to form a solution at a constant concentration of $10 \%$ acrylamide and six concentrations of $0.03,0.07,0.13,0.26,0.30$, and $0.60 \%$ bisacrylamide. After adding $1 / 200(\mathrm{v} / \mathrm{v})$ of $10 \%$ ammonium peroxydisulfate (curing agent) and $1 / 2000(\mathrm{v} / \mathrm{v})$ of $N, N, N^{\prime}, N^{\prime}$-tetramethylethylenediamine (accelerating agent) into the PA mixture, the designed mask with planar or topographical geometry was suspended immediately for $50 \mathrm{~min}$ at room temperature (RT). Solidified PA hydrogel was then removed carefully and spoiled in deionized water overnight (Fig. S1a). An adequate volume of $0.2 \mathrm{mg} / \mathrm{ml}$ of sulfo-SANPAH solution (cross-linking agent) was added, and then was irradiated in ultra-violet light for $5 \mathrm{~min}$. After complete washing, $1 \mathrm{ml}$ of $20 \mu \mathrm{g} / \mathrm{ml}$ collagen I was added and cross-linked securely onto the PA hydrogel surface.
To quantify the mechanical stiffness of the substrate, the planar PA hydrogel at each of six bis-acrylamide concentrations was cut into rectangular stripes $(L: W: H=5: 2: 0.1 \mathrm{~cm})$. The strain, defined as $\Delta L / L$, was measured using a selfweighing assay, which produces its Young's modulus by applying $E=(G / A) /(\Delta L / L)$ where $G$ and $A$ are the weight and section area, respectively (Fig. S1b). In the current study, $E=6.1,14.9,18.8,42.5,46.7$, and $63.4 \mathrm{kPa}$, respectively, at the six concentrations of bis-acrylamide (Fig. S1c), in which two sets of stiffness of the PA hydrogel with $E=6.1$ and $46.7 \mathrm{kPa}$ were used in the following functional tests. Finally, the PA hydrogel was prepared in the form of discs $(20 \mathrm{~mm}$ in diameter and $0.1 \mathrm{~mm}$ in thickness), two types of topographies (square pillar and groove) and three sets of dimensions (pillar side-length/inter-pillar gap size or groove ridge width/ditch width $=5 / 15,10 / 10$, or $15 / 5 \mu \mathrm{m}$ ) with a depth of $5 \mu \mathrm{m}$ were employed, whereas the planar PA hydrogel was used as the control (cf. Fig. 1).

\subsection{Cells and reagents}

rBMSCs were isolated from 3- to 4-week-old male Sprague-Dawley (SD) rats (Vital River Laboratory Animal Technology Company, Beijing, China). Briefly, the animal was sacrificed by cervical dislocation, and the femur and tibia were collected. The bone marrow was flushed out, and the collected cell suspension was added to LDMEM medium (Gibco, USA) supplemented with $10 \%$ fetal bovine serum and $1 \mathrm{ng}$ / $\mathrm{ml}$ bFGF in a T-25 flask or 12-well plastic plate. Adherent cells were then maintained in a humidified, $95 \%$ air $/ 5 \% \mathrm{CO}_{2}, 37^{\circ} \mathrm{C}$ incubator by refreshing the medium every two or three days. When grown to 85-90\% confluence, the cells were rinsed in $\mathrm{Ca}^{2+}$ - and $\mathrm{Mg}^{2+}$-free PBS, and then were detached using 0.25\% trypsin-EDTA for $1 \mathrm{~min}$. This procedure was repeated three or four times to collect rBMSCs at $\sim 90 \%$ purity.

Goat-anti-rat anti-CD11b, CD34, CD45, and CD90 monoclonal antibodies (mAbs) were purchased from Santa Cruz Biotechnology (USA). Mouse-anti-rat anti-Runx2, rabbit-anti-rat anti- $\beta$-tubulin III mAbs, goat-anti-mouse IgG-FITC, and mouse-antirabbit IgG-FITC were from Sigma (USA). FITC-conjugated phalloidin was from Enzo (USA). Rabbit-anti-rat Alexa Fluor ${ }^{\circledR} 647$ conjugate anti-vimentin (D21H3) XP ${ }^{\circledR}$ and Alexa Fluor ${ }^{\circledR} 555$ conjugate anti- $\alpha$-tubulin (11H10) mAbs were from Cell Signaling Technology (USA).

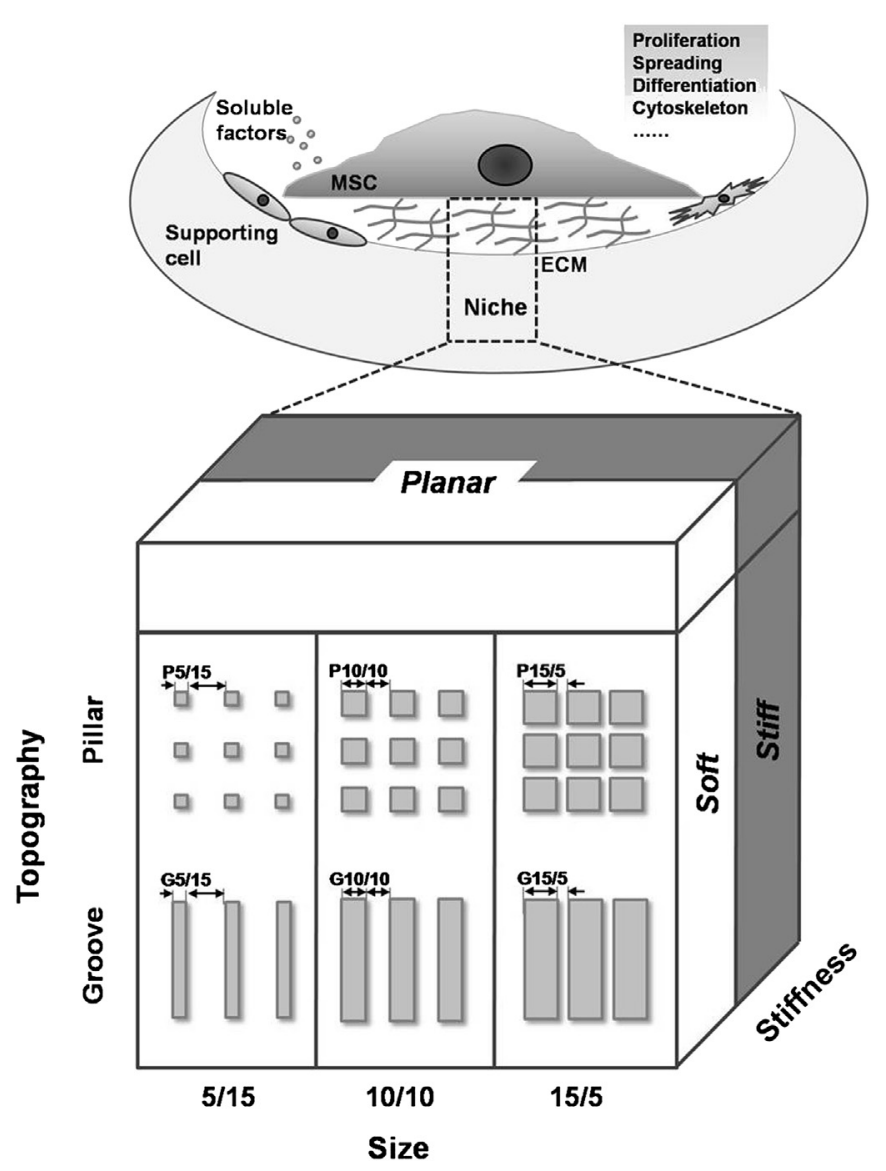

Fig. 1. Schematic of experimental set-up. Systematically tested are the three regulating factors of stiffness, topography, and dimension of PA hydrogel substrate. Planar substrate at varied stiffness was used as control. 


\subsection{Flow cytometry and immunological staining}

Expression of biomarkers of rBMSCs was performed using flow cytometry. Briefly, cells were incubated with $10 \mu \mathrm{g} / \mathrm{ml}$ of anti-CD11b, CD34, CD45, or CD90 mAbs separately for $45 \mathrm{~min}$ on ice. Collected cells were incubated with $10 \mu \mathrm{g} / \mathrm{ml}$ of FITC-conjugated secondary polyclonal antibodies, and then were analyzed using a FACSCanto II flow cytometer (Becton-Dickinson, USA). The pluripotency of isolated rBMSCs was identified with high expression of CD90, but null expression of CD11b, CD34, and CD35 (Fig. S2a), when the cells were cultured in flasks (Fig. S2b).

Distribution of cytoplasmic proteins, actin, vimentin, or vinculin, was visualized using immunostaining techniques. Cells cultured on the substrate were rinsed in $\mathrm{PBS}$ at $\mathrm{pH} 7.2$, fixed for $30 \mathrm{~min}$ in $4 \%$ paraformaldehyde, and permeabilized with $0.1 \%$ Triton $100-\mathrm{X}$ for $15 \mathrm{~min}$. Filamentous actin was stained with FITC-conjugated phalloidin diluted in $1 \%$ bovine serum albumin/PBS to block nonspecific epitopes. Anti-vimentin and anti- $\alpha$-tubulin mAbs were added at 1:800 and 1:50 in BSA/PBS, respectively. Next, samples were incubated with Hoechst 33342 for $10 \mathrm{~min}$ at RT and washed twice with PBS. The collected samples were then stored at $4{ }^{\circ} \mathrm{C}$ followed by examination by confocal laser scanning microscopy (Zeiss L710, Germany).

In some cases, actin staining was used to help identify the contour of a cell. The projected area of the cell was then measured to determine the cell morphology. Cell circularity was defined as $4 \pi \times$ area/perimeter ${ }^{2}$ for quantitative comparison. For each topographical substrate, no less than 27 cells were counted and analyzed.

\subsection{SEM imaging of cells}

rBMSCs were seeded initially at 1000 cells $/ \mathrm{cm}^{2}$ and collected at day 2 . After being washed three times in $\mathrm{Ca}^{2+}$ - and $\mathrm{Mg}^{2+}$-free PBS, cells were fixed with $0.25 \%$ glutaraldehyde at RT overnight. By removing the glutaraldehyde with deionized water, fixed cells were dehydrated in gradient ethanol and finally dried in a vacuum for $4 \mathrm{~h}$. Image analysis was performed using a scanning electron microscope (SEM) (Nova 200 NanoLab scanning electron microscope, USA).

\subsection{Cell proliferation and differentiation}

Proliferation of rBMSCs seeded at a density of 5000 cells $/ \mathrm{cm}^{2}$ was quantified by counting the cells daily. The proliferation rate was defined as the ratio of the cell number at day 3 to that at day 0 . In some cases, the rate was estimated every day, and the time course of cell proliferation was obtained up to day 5 .

The differentiation of rBMSCs seeded at a density of 3000 cells $/ \mathrm{cm}^{2}$ was tested at day 3 via an immunostaining technique. Similar to the cytoskeletal protein analysis, fixed, permeabilized cells were stained with $10 \mu \mathrm{g} / \mathrm{ml}$ of anti-Runx2 or anti- $\beta 3$ tubulin mAbs, and then were incubated with respective FITC-conjugated secondary antibodies. Relative fluorescence intensity (RFI) was estimated using Image software, and then was normalized by the value for its own nuclei.

\subsection{Statistical analysis}

Student's two-tailed $t$-test was performed to determine the statistical significance of differences between any two parameters of twelve cases on topographical substrate for cell proliferation, morphology, differentiation, and cytoskeletal remodeling. To further compare the respective contribution of the three regulating factors of stiffness, topography, and dimension, N-way Anova F-test was also conducted to determine the predominance of differences between these cellular phenotypes on the three sets of parameters. Linear and interaction algorithms obtained from Matlab software were used to estimate the $P_{F}$ values for substrate stiffness, topography, and dimension.

\section{Results}

\section{1. $r B M S C s$ on $3 D$ and planar substrates}

To mimic the biological responses of rBMSCs under the 3D niche (cf. Fig. 1), the features of the PA hydrogel substrate was systematically tested using the substrate stiffness, topography, and dimension. Substrate stiffness was given at $E=46.7$ (stiff) and 6.1 (soft) $\mathrm{kPa}$, substrate topography was set in square pillar and groove configurations, and substrate dimension was varied by three settings of side-length/inter-pillar gap size (pillar) or ridge width/ ditch width (groove) $=5 / 15,10 / 10$, or $15 / 5 \mu \mathrm{m}$. Planar PA hydrogel was used as the control (Fig. 1).

As a positive control, the impact of substrate stiffness for rBMSCs was briefly tested on the planar PA substrate. As exemplified in Fig. S3, the cells preserved their branched (a, d) or elongated (b, e) shape on the stiff or soft substrate, respectively. No significant difference in cell growth (c) and circularity and area (f) was found between the stiff or soft substrate. Osteogenic or neuronal differentiation was identified by Runx 2 or $\beta 3$-tubulin expression for cells placed on the stiff or soft substrate, respectively (i). Although actin expression was comparable between the stiff and soft substrate, the expression of vimentin and $\alpha$-tubulin was higher on the stiff substrate than on the soft substrate. These brief results supported the existing observations that substrate stiffness regulates rBMSC proliferation, morphology, differentiation, and cytoskeletal reorganization [5,13,24,25,28,35,36].

\subsection{Stiffness or dimension to rBMSC proliferation}

We first compared cell proliferation on various substrates at day 3 (Fig. 2a-d). It was found that stiffness likely affected rBMSC proliferation on an evenly dimensioned substrate, as shown by the proliferation rate being higher on the stiff substrate than on the soft substrate, either with a pillar dimension of $10 / 10$ (shortly, P10/10) (3.49 \pm 0.96 and $2.50 \pm 0.42$, respectively; $P=0.042$ ) or with a grooved dimension of 10/10 (shortly, G10/10) (4.22 \pm 1.00 and $2.18 \pm 0.84$, respectively; $P=0.003$ ) (Fig. 2e). By contrast, no significant difference in the rate was found between the stiff and soft substrate with the same topography and uneven dimension. Topography most unlikely manipulated rBMSC proliferation between pillar and groove substrates because no remarkable difference in the proliferation rate was found in each pair of cases with the same stiffness and dimension. Dimension can also regulate rBMSC proliferation on substrates with the same stiffness and topography, as demonstrated by the rate being higher on the unevenly dimensioned P15/5 substrate than on the evenly dimensioned P10/10 substrate, either with a stiff $(5.24 \pm 1.43$ and $3.49 \pm 0.96$, respectively; $P=0.048)$ or a soft $(3.57 \pm 0.86$ and $2.50 \pm 0.42$, respectively; $P=0.029$ ) surface (left panel). By contrast, no significant difference was found between any two cases of a distinctly dimensioned, grooved substrate (right panel) (Fig. 2e). These results suggested that both stiffness and dimension, but not topography, affect rBMSC proliferation. Additionally, the stiffer and more unevenly dimensioned the substrate is, the higher the magnitude of cell growth that is yielded.

$\mathrm{N}$-way Anova analysis was employed to further test the predominance of these factors. $P_{F}$ yielded $0.000,0.503$, and 0.013 from the linear analysis for stiffness, topography, and dimension, respectively, with an order of predominance as stiffness $>$ dimension $>>$ topography. This result is similar to the aforementioned observations. Further interaction analysis was also performed to test the potential interplay of any two of the three factors. Data were presented as $P_{F}=0.189,0.437$, and 0.352 for the respective combination of stiffness $\oplus$ topography, stiffness $\oplus$ dimension, and topography $\oplus$ dimension, indicating that no interplay was found among the three factors. Taken together, these results suggested that the predominance of the three factors follows the order stiffness $>$ dimension $>>$ topography, and the interplay of the factors would be excluded in regulating rBMSC proliferation.

\subsection{Topography or stiffness to rBMSC morphology}

Following the same line of comparison, we tested the impact of the three factors on cell morphology by defining the circularity as $4 \pi \times$ perimeter $^{2} /$ area for isolated cells. No significant difference in cell circularity was found when stiffness or dimension is varied. Topography alone can alter the cell morphology in three of six paired cases - i.e., between P5/15 and G5/15 (0.13 \pm 0.02 and $0.08 \pm 0.02$, respectively; $P=0.021)$ on the stiff substrate or between $\mathrm{P} 10 / 10$ and $\mathrm{G} 10 / 10(0.14 \pm 0.01$ and $0.10 \pm 0.02$, respectively; $P=0.014)$ and between $P 15 / 5$ and G15/5 (0.15 \pm 0.03 and $0.09 \pm 0.01$, respectively; $P=0.041$ ) on the soft substrate (Fig. 3a). 

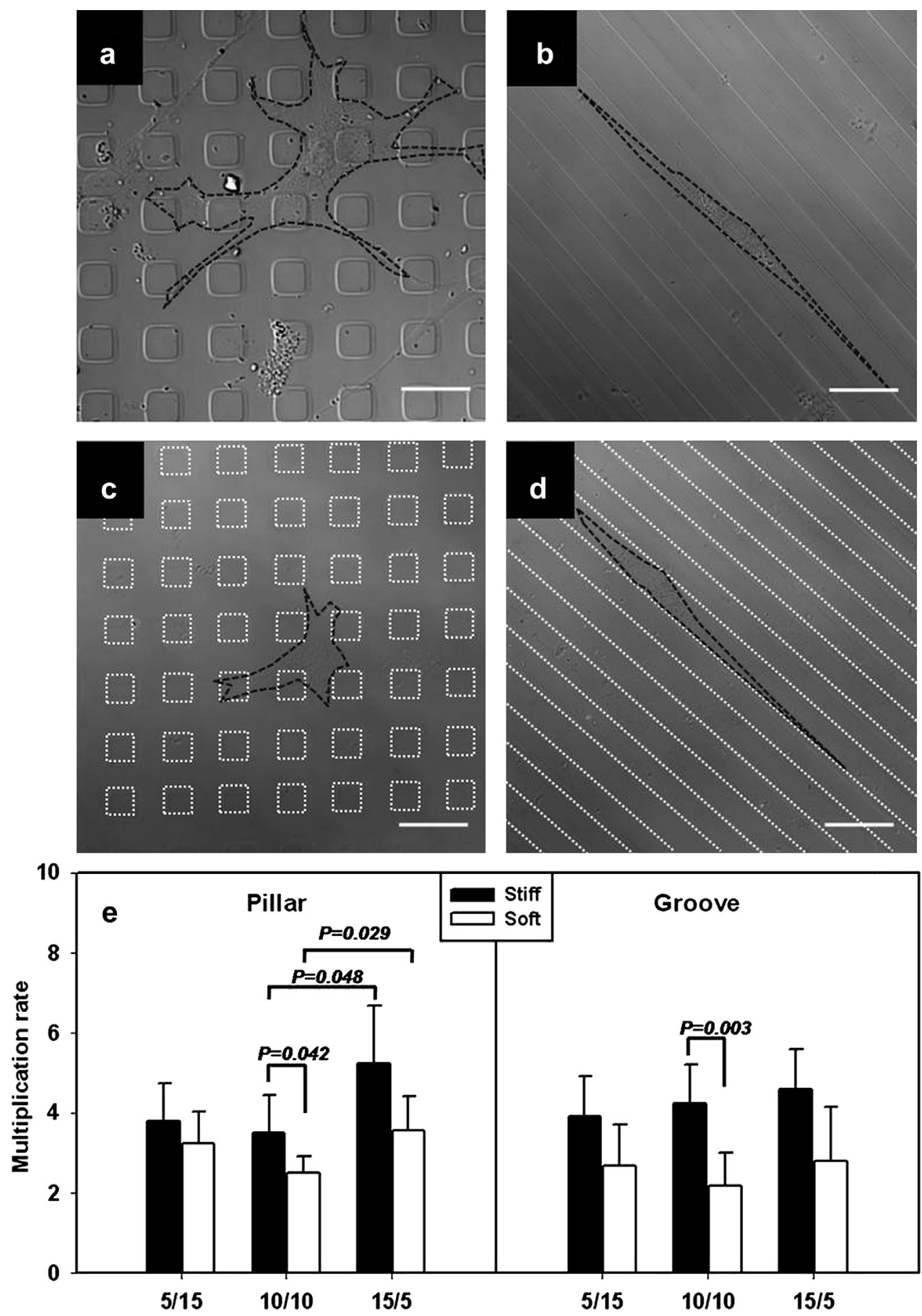

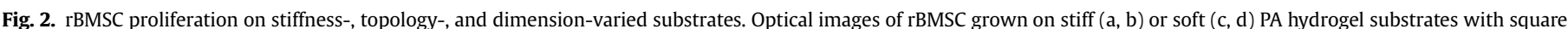

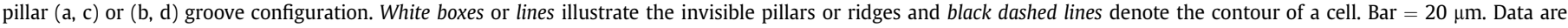
presented as the mean \pm standard deviation (SD) of proliferation ratio at day 3 in sextuplet (evenly-dimensioned cases) or quadruplet (unevenly-dimensioned cases) (e).

These results suggested that substrate topography is a key factor to regulate rBMSC morphology. Further predominance tests indicated that $P_{F}=0.011,0.000$, and 0.574 from the linear analysis for stiffness, topography, and dimension, respectively. Not only did this test support that topography is a key factor, but the test also unraveled a new important factor, substrate stiffness, in manipulating cell circularity. Again, no interplay was found between any two of the three factors from the interaction analysis (all the values, $P_{F}>0.50$ ). Thus, these results suggested that the predominance of the three factors follows the order topography $>$ stiffness $>>$ dimension in regulating rBMSC morphology.
We further tested the effect of these factors on cell spreading ( $c f$. Fig. $2 \mathrm{a}-\mathrm{d}$ and Fig. S4a-i). It was indicated that topography alone can modulate the cell projected area in three of six cases between P5/15 and G5/15 (1874 \pm 74 and $1305 \pm 171 \mu \mathrm{m}^{2}$, respectively; $\left.P=0.006\right)$ and between P10/10 and G10/10 (1742 \pm 215 and $1298 \pm 93 \mu \mathrm{m}^{2}$, respectively; $P=0.030$ ) on the stiff surface, or between $P 5 / 15$ and $\mathrm{G} 5 / 15$ on the soft surface $\left(1752 \pm 235\right.$ and $1203 \pm 165 \mu \mathrm{m}^{2}$, respectively; $P=0.030$ ). By contrast, area difference was also found in one paired case for stiffness alone between stiff and soft G10/10 (1298 \pm 93 and $1526 \pm 91 \mu \mathrm{m}^{2}$, respectively; $P=0.039$ ) or for dimension alone between G10/10 and G5/15 on the soft surface 

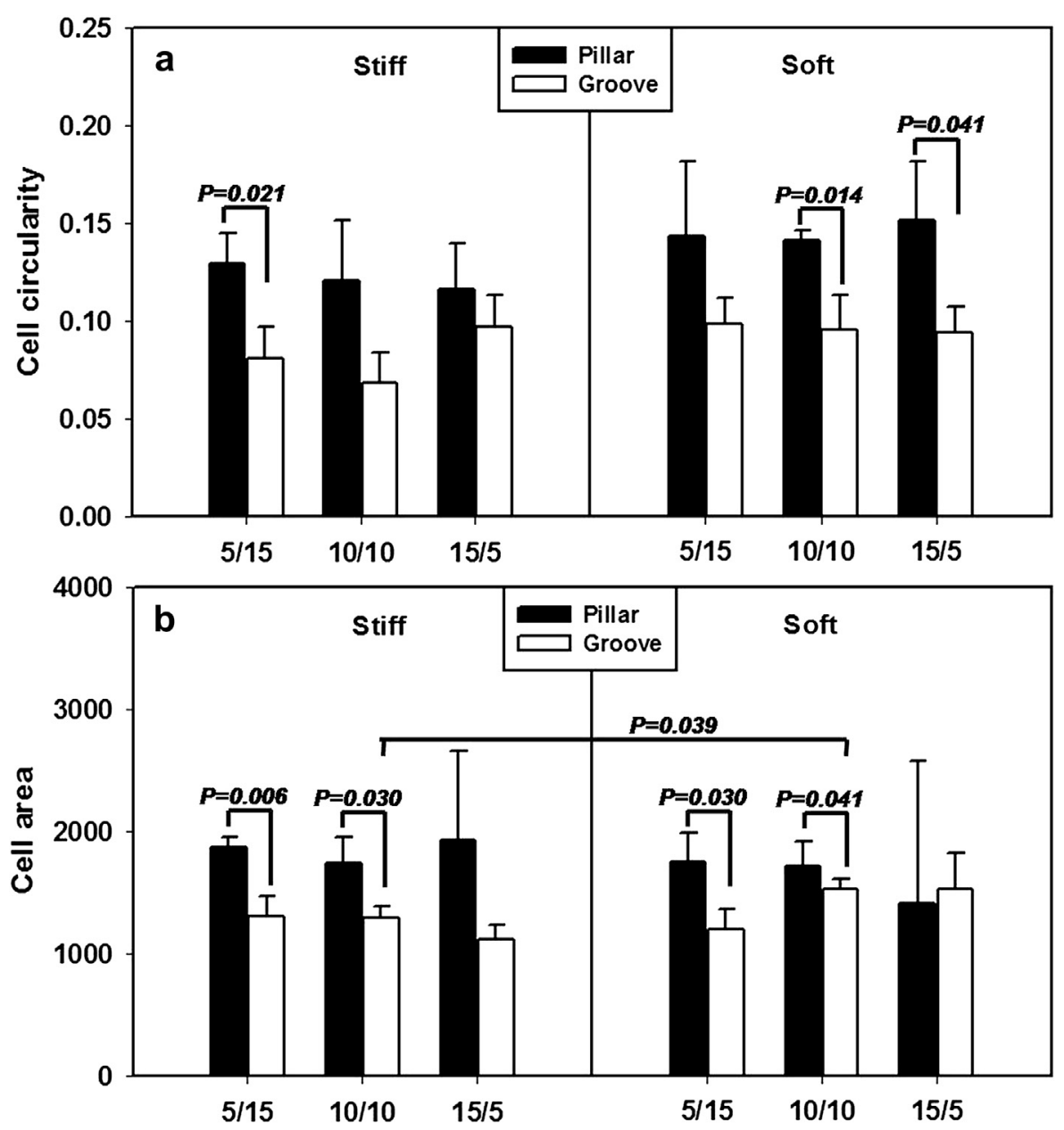

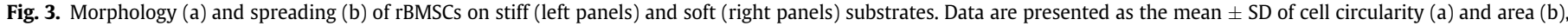
respectively, at day 3 in sextuplet (evenly-dimensioned cases) or quadruplet (unevenly-dimensioned cases).

(1526 \pm 91 and $1203 \pm 165 \mu \mathrm{m}^{2}$, respectively; $P=0.041$ ) (Fig. 3b). These results suggested that topography is a core regulator, whereas the stiffness or dimension is much less sensitive in regulating rBMSC spreading. Linear $F$-test analysis also presented a much lower $P_{F}$ value (0.006) for topography than that for stiffness (0.877) and dimension (0.912). No interplay was found between any two of the three factors from the interaction analysis (all the values, $P_{F}>0.15$ ). Thus, these data implied that the predominance of the three factors follows the order topography $>>$ stiffness $\approx$ dimension in regulating rBMSC spreading.

\subsection{Stiffness to rBMSC differentiation}

It has been known that multi-lineage differentiation of MSCs is mainly regulated by substrate stiffness $[5,19,23]$. We further tested the impact of the three factors on two lineages of osteogenic and neuronal differentiation. The relative fluorescence intensity (RFI) of Runx2 or $\beta 3$-tubulin was used to identify the differentiated lineage of osteoblasts or neurons, respectively.

In osteogenic differentiation, Runx2 expression was well observed on the stiff, but not soft, substrate (Fig. S5a), with a pillar $(R F I=1.61 \pm 0.25$ and $0.03 \pm 0.02$ for $\mathrm{P} 10 / 10 ; P=0.004)$ (cf. Fig. $4 \mathrm{a})$ or grooved $(1.47 \pm 0.45$ and $0.05 \pm 0.02$ for $\mathrm{G} 10 / 10 ; P=0.024)(c f$. Fig. $4 c$ ) configuration. This observation supported that rBMSCs tend to differentiate into osteoblasts on the stiff substrate as expected $[5,17]$. Interestingly, topography alone has less impact but is still effective in osteogenic differentiation because Runx2 expression is significantly different in an unevenly dimensioned case between $\mathrm{P} 15 / 5$ and $\mathrm{G} 15 / 5(2.28 \pm 0.23$ and $1.34 \pm 0.30, P=0.012)$. This dimension-dependent difference was also observed on the stiff substrate with a pillar, but not grooved, configuration, between $\mathrm{P} 15 / 5$ and $\mathrm{P} 10 / 10(2.28 \pm 0.23$ and $1.61 \pm 0.25 ; P=0.026)$ or $\mathrm{P} 15 / 5$ and $\mathrm{P} 5 / 15(2.28 \pm 0.23$ and $1.61 \pm 0.33 ; P=0.045)$ (left panel in Fig. 4e). These results implied that osteogenic differentiation of rBMSCs on the stiff substrate favors a square pillar configuration that is unevenly dimensioned with a large side length but a small inter-pillar gap size. The predominance order of stiffness > topography $\approx$ dimension in regulating osteogenic differentiation of rBMSCs was then proposed by linear F-test analysis where $P_{F}=0.000,0.010$, and 0.105 , respectively. Thus, these results suggested that osteogenic differentiation of rBMSCs prefers to be placed on a stiff, pillar substrate with an uneven dimension.

Similarly, $\beta 3$-tubulin expression was well observed on the soft, but not stiff, substrate (Fig. S5b), with a pillar $(0.07 \pm 0.02$ and $0.01 \pm 0.00$ for $\mathrm{P} 10 / 10 ; P=0.023$ ) (cf. Fig. $4 \mathrm{~b}$ ) or grooved $(0.27 \pm 0.07$ and $0.01 \pm 0.00$ for G10/10; $P=0.002)(c f$. Fig. $4 d)$ configuration, as reported previously for neuronal differentiation of rBMSCs [5-7,35]. Topography plays a role in neuronal differentiation, as observed in the difference in $\beta 3$-tubulin expression between $\mathrm{P} 10 / 10$ and $\mathrm{G} 10 / 10(0.07 \pm 0.02$ and $0.27 \pm 0.07 ; P=0.007)$ or P15/5 and G15/5 (0.04 \pm 0.01 and $0.06 \pm 0.00 ; P=0.030)$. These results implied that neuronal differentiation of rBMSCs on the soft 

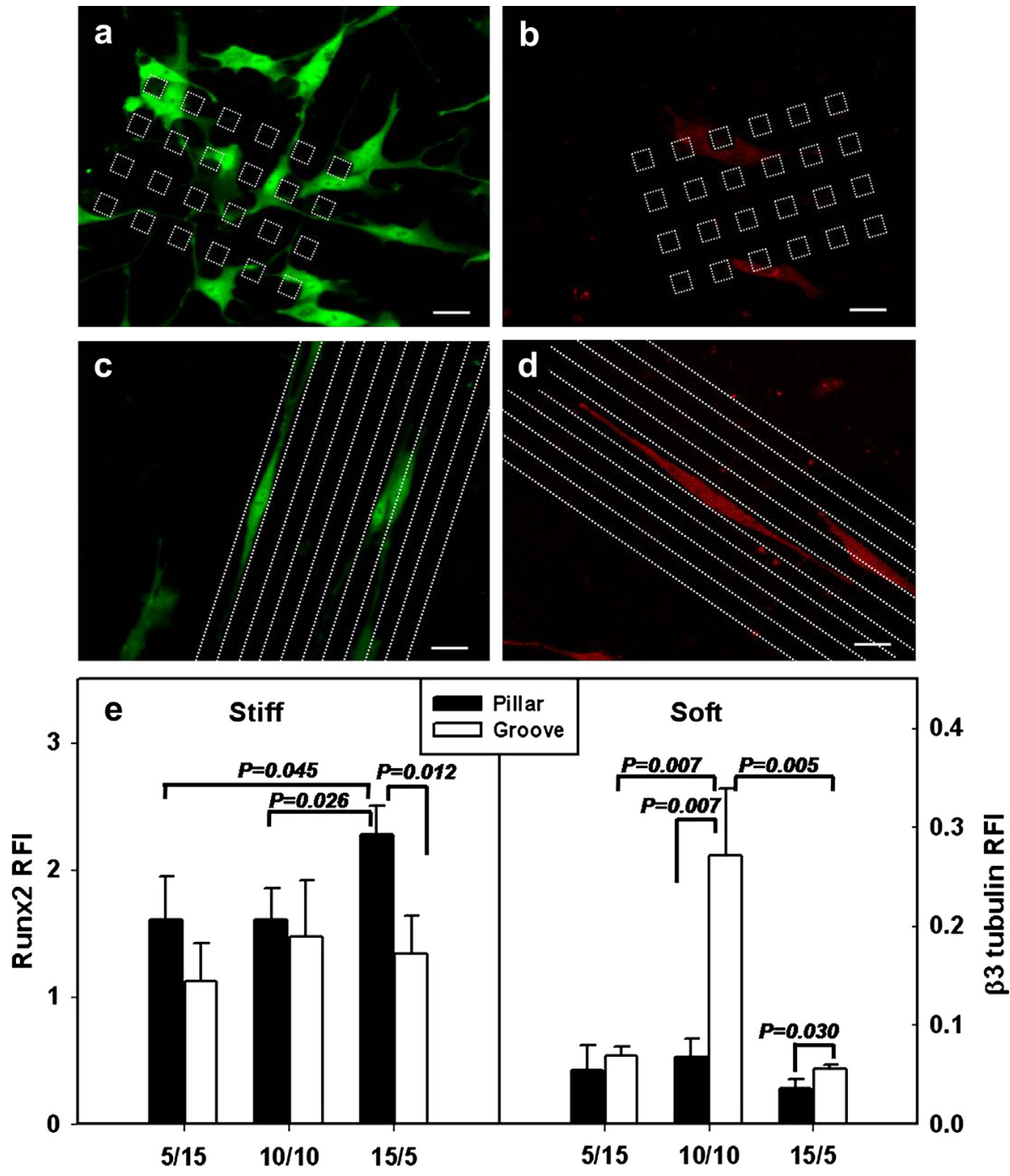

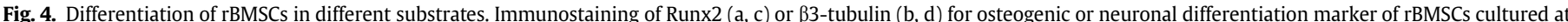

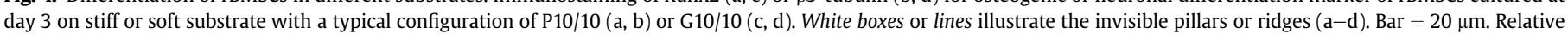

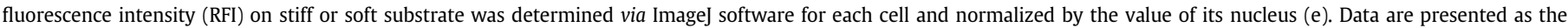
mean \pm SD of averaged values for total $\geq 27$ cells in triplet.

substrate favors a grooved configuration that is evenly dimensioned. A dimension-dependent difference was observed on the soft substrate mainly with the grooved, but not pillar, configuration, between G5/15 and G10/10 $(0.07 \pm 0.01$ and $0.27 \pm 0.07, P=0.026)$ or G10/10 and G15/5 $(0.27 \pm 0.07$ and $0.06 \pm 0.003, P=0.045)$ (right panel in Fig. 4e). Again, the predominance order of stiffness $>$ dimension $\approx$ topography in regulating neuronal differentiation of rBMSCs could be proposed by the linear F-test analysis where $P_{F}=0.000,0.013$, and 0.002 , respectively. Thus, these results implied that neuronal differentiation of rBMSCs prefers to be placed on a soft, groove substrate with even dimension.

\section{5. rBMSC cytoskeletal re-organization}

Stem cell responses to different substrates are highly associated with cytoskeletal structure $[14,15,28,35]$. We next tested the impact of the three factors in the re-organization of three major cytoskeletal components - actin, vimentin, and $\alpha$-tubulin - by quantifying their RFI values from immunostaining tests.

For actin re-organization, the microfilaments spread out extensively on the stiff substrate (Fig. 5a and c) compared with the filaments on the soft substrate (Fig. 5b and d). The filaments also yielded a large area in a typical pillar P10/10 configuration (Fig. 5a-b) compared with that in a groove G10/10 configuration (Fig. $5 c-d$ ), similar to the aforementioned observation in the projected area ( $c f$. Fig. 3b). Such a distribution of actin was also observed in other dimensioned substrates (data not shown). Stiffness, topography, or dimension did not affect actin expression independently because no significant difference was found in RFI values between each paired case $(=0.71-1.13$; all the values; $P>0.15$ ) (Fig. 5e). No significant difference was found from the interaction $F$-test analysis, that is, $P_{F}=0.687,0.647$, and 0.448 , for the respective combination of stiffness $\oplus$ topography, stiffness $\oplus$ dimension, and topography $\oplus$ dimension.

For vimentin re-organization, the intermediate filaments was likely distributed close to the nucleus of the cell on the stiff (Fig. $5 \mathrm{f}$ and $\mathrm{h}$ ) or soft (Fig. $5 \mathrm{~g}$ and i) substrate in a typical pillar P10/10 (Fig. 5f-g) or groove G10/10 (Fig. 5h-i) configuration. Such distribution of vimentin was also observed in other dimensioned substrates (data not shown). Again, stiffness, topography, or dimension did not affect vimentin expression independently, as observed in the indifferent RFI values between each paired case $(=0.13-0.42$; all the values, $P>0.06$ ) (Fig. $5 \mathrm{j}$ ). However, a seemingly combinatory 

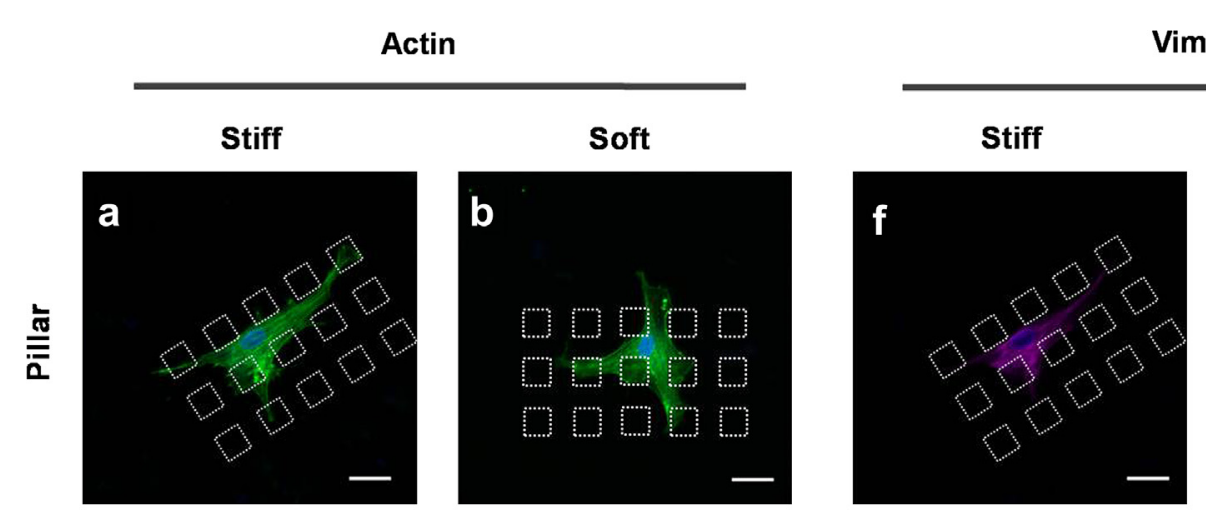

Vimentin
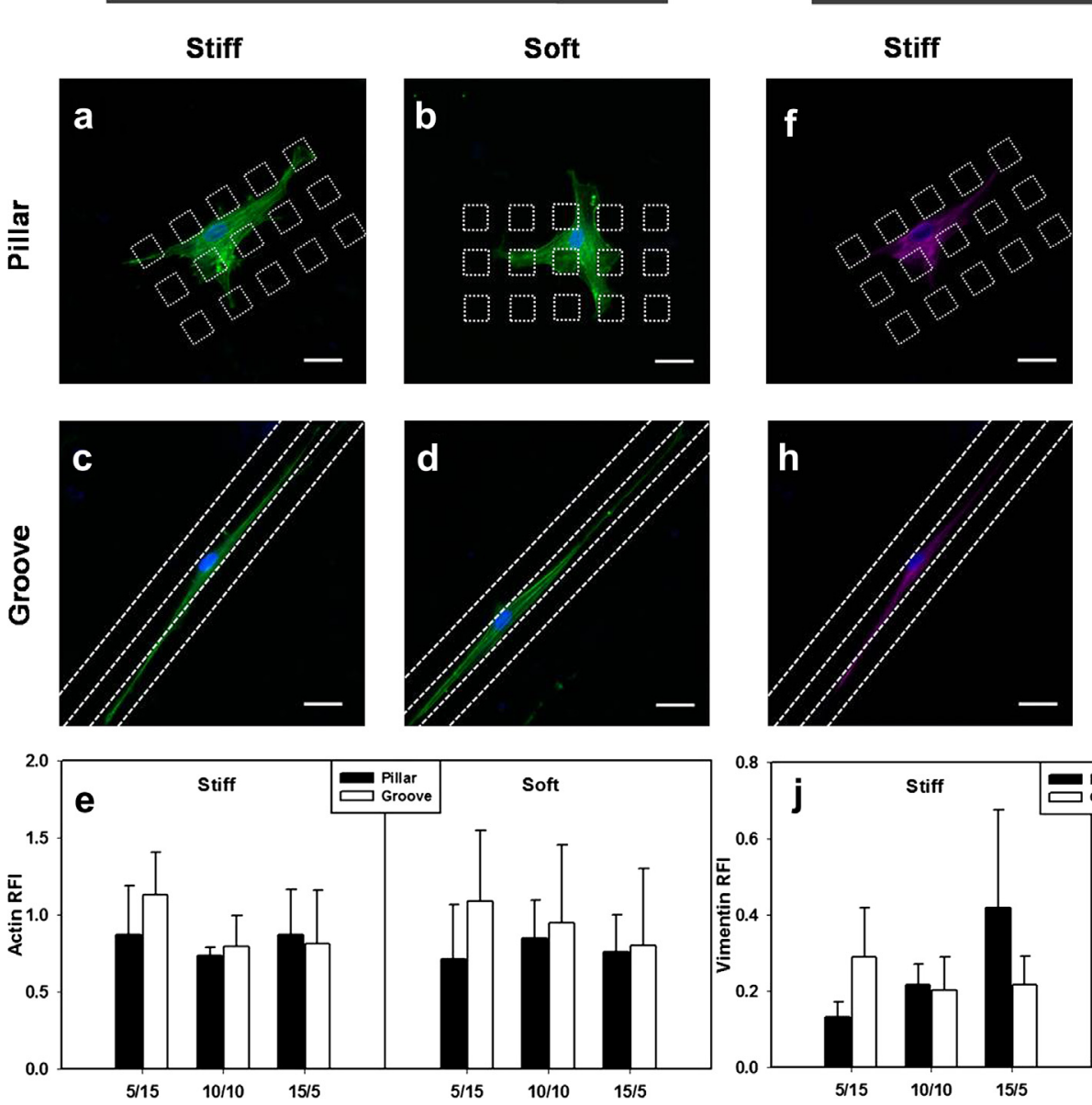
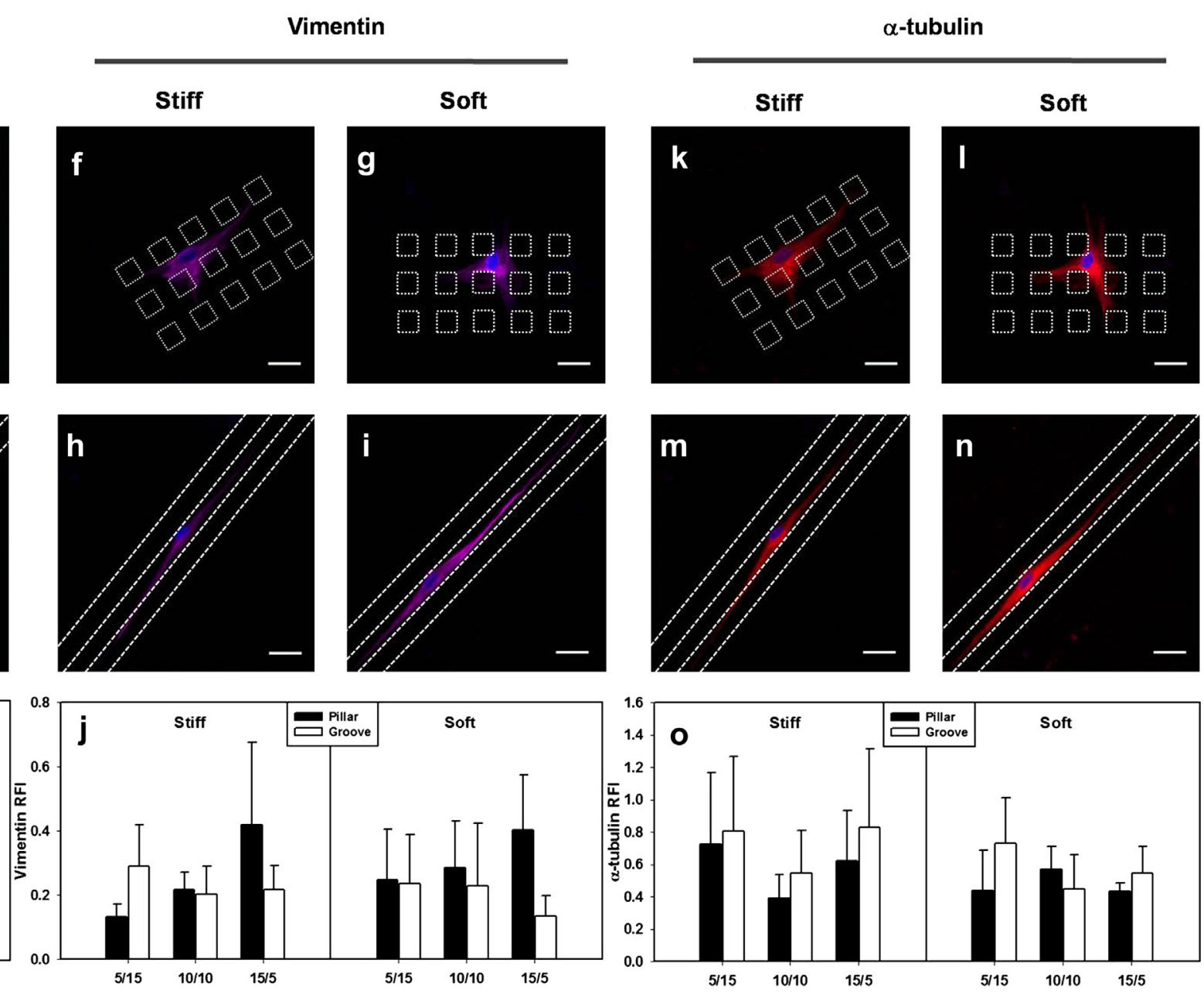

Fig. 5. Cytoskeletal structure of rBMSCs in different substrates. Immunostaining of actin (a-d), vimentin ( $\mathrm{f}-\mathrm{i})$ or $\alpha$-tubulin $(\mathrm{k}-\mathrm{n})$ of $\mathrm{rBMSCs}$ cultured at day 3 on stiff or soft substrate with a typical configuration of P10/10 (1st row) or

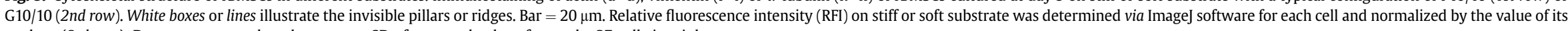
nucleus (3rd row). Data are presented as the mean \pm SD of averaged values for total $\geq 27$ cells in triplet. 
impact, even much less, was still observed from the interaction $F$-test analysis by $P_{F}=0.034$ for topography $\oplus$ dimension, whereas $P_{F}=0.319$ and 0.660 for the respective combination of stiffness $\oplus$ topography and stiffness $\oplus$ dimension. $P_{F}$ was then recalculated, using the main factor algorithm within the interaction model, to be $0.686,0.157$, and 0.441 for stiffness, topography, and dimension, respectively, which turned out to be the possible predominance order of topography $>$ dimension $>$ stiffness in regulating jointly the vimentin network of rBMSCs.

For $\alpha$-tubulin re-organization, the microtubule distribution was similar to that for actin on the stiff (Fig. 5k and m) or soft (Fig. 51 and $\mathrm{n}$ ) substrate in the pillar or groove configuration, not only with a typical dimension of P10/10 (Fig. 5k-1) or G10/10 (Fig. 5m-n) but also with the other dimensioned substrates (data not shown). Stiffness, topography, or dimension did not affect $\alpha$-tubulin expression independently, as observed in the indifferent RFI values between each paired case ( $=0.39-0.83$; all the values, $P \geq 0.20$ ) (Fig. 5o). Distinctly, no interplay between any two of the three factors was observed from the interaction $F$-test analysis by $P_{F}=0.782,0.485$, and 0.758 , for the respective combination of stiffness $\oplus$ topography, stiffness $\oplus$ dimension, and topography $\oplus$ dimension, implying that no combinatory impact of the three factors exists in regulating the $\alpha$-tubulin network of rBMSCs.

\section{Discussion}

In the present study, we sought to determine the independent or combinatory effect of stiffness, topography, and/or dimension of substrates in regulating the proliferation, morphology, differentiation, and cytoskeletal re-organization of rBMSCs. Using limited but typical combinations of the parameters, we proposed the distinct roles of the three regulating factors in different cell functions. The predominant impact of a single factor was mainly found for stiffness or dimension to proliferation, topography or stiffness to morphology, and stiffness to differentiation, but none to cytoskeletal re-organization. By contrast, the seemingly combinatory effects were demonstrated for topography $\oplus$ dimension to vimentin. To the best of our knowledge, this is the first study to map systematically the respective contribution of the three factors and rank their importance in rBMSC functions, shedding light on how to replicate the in vivo 3D niche using an in vitro approach.

Physical clues or mechanical forces regulate stem cell functions through changing the cell shape and altering cytoskeletal network [37]. Stiff matrix is favorable for MSC proliferation by up-regulating the expressions of cell adhesive molecules to develop an equal, opposite counterbalancing forces to the substratum. Dimensional unevenness of topographic substrate also promotes MSC growth presumably due to direct the cells grow up in a less confined manner. MSC morphology is mainly governed by substrate topography upon contact guidance and topographic reaction, in which the substrate stiffness also plays an important role in regulating cell spreading (circularity and projected area) by altering the capacity of cell adhesion on a stiff or soft substrate. Moreover, not only the substrate stiffness determines the fate of MSCs through altering cell traction force and changing the nuclear translocation of transcript factors, but the substrate topography and dimension also regulate MSC differentiation by modifying the distribution of focal adhesion complexes and in turn modulating the cell traction [38]. While these physical or mechanical signals present the differential effects on stem cell functions, the related downstream pathways (integrin, RhoA, and ROCK) need to be clarified in the future work. Thus, a well-defined 3D substratum with appropriate stiffness, topography, and dimension is crucial to control stem cell behaviors in stem cell biology and engineered tissue construction.
Such a differential effect is biologically relevant because substrate stiffness, topography and dimension are usually coupled in the in vivo 3D stem cell niche. First, substrate stiffness or dimension tends to be more sufficient than topography in regulating stem cell proliferation. The hMSC proliferation rate increases up to 10 -fold with the increase of stiffness from 0.7 to $80 \mathrm{kPa}$ on the PA substrate [13], and murine ESC proliferation is enhanced from $41 \mathrm{kPa}$ to 2.3 MPa on the PDMS substrate [39], findings that are consistent with our observation that the stiff PA substrate at $46.7 \mathrm{kPa}$ is favorable to promote rBMSC proliferation (Fig. S3c). It should be noted that stiffness usually works in a cell- and material-specific manner because no difference in hMSC proliferation is found between the stiff and soft gelatin hydroxyphenylpropionic acid hydrogels [40], or even neural stem or progenitor cells prefer to proliferate on the soft methacrylamide chitosan substrate [41]. Moreover, substrate dimension also plays a potential role in stem cell proliferation, as observed by the proliferation rate of canine MSCs being significantly higher on $2-\mu \mathrm{m}$ ridge and groove surfaces than that on 0.4-, 0.8-, 1.2-, 1.6-, and 4- $\mu$ m surfaces [42], or by the rMSCs tending to proliferate on microhilled chitosan with a diameter of 5-30 $\mu \mathrm{m}$ but not $10 \mu \mathrm{m}$ [43]. Our data also indicated that substrate dimension is more critical than its topography in this regard (Fig. 2). Next, substrate topography or stiffness is more sensitive than dimension to manipulate stem cell morphology and spreading. A grooved topography is well known to promote the directed alignment of various stem or precursor cells in the literature [44-47] as well as in the current study (Fig. 2b, d, and Fig. S4). The microarrays made of the poly(epsilon-caprolactone) shapememory polymer can control hMSC morphology on dynamic topographies that are hexagon, circle, square, right angle, or groove shaped [48], supporting that substrate topography is the leading factor to regulate cell morphology and spreading by sensing and responding to external stimulus in vivo. In addition, we further presented that rMSCs on the stiff pillar substrate is more elongated than those on the soft substrate (Fig. 3a-b), implying that stiffness also plays a role in regulating cell morphology. Finally, substrate stiffness is well known to be predominate in promoting stem cell differentiation, as observed for the respective osteogenic and neuronal differentiation of hMSCs on bone-like (25-40 kPa) and brain-like (0.1-1 kPa) stiffness [5,35] and neuronal differentiation of rMSCs on stiff ( $46.7 \mathrm{kPa}$ ) and soft (6.1 kPa) planar PA substrates (Figs. S3g-i and S5). Moreover, we proposed here that topography or dimension is complementarily effective in the two lineage fates of rBMSCs to some extent (Fig. 4). In fact, it has been noticed that the ordered, but not randomized, topographical substrate is sufficient to induce hMSC osteogenic differentiation [30,49], and grooved topography favors axon growth and guidance of the neuronal response of MSCs [50], consistent with our findings that the pillar or groove topography induces relatively higher expression of Runx2 and $\beta 3$-tubulin (Fig. 4e) than those on the planar substrate (Fig. S3i). In addition to the known impact of nanoscale dimensioned topography [24,31,32], micro-scale dimension dependence of stem cell differentiation has also been observed such that the intermediate width/spacing $(40 / 30 \mu \mathrm{m})$, but not the larger $(80 / 40 \mu \mathrm{m})$ or smaller dimension $(30 / 20 \mu \mathrm{m})$ of the micropatterned ridge, induces the neuronal phenotype of hMSCs [51]. Similar dimension dependence was found in the current study where rBMSCs favor placement on an unevenly dimensioned substrate for osteogenic differentiation and on an evenly dimensioned substrate for neuronal differentiation (Fig. 4e). Taken together, our data further the understanding of differential effects of substrate stiffness, topography, and dimension on the biological functions of rBMSCs.

Moreover, such findings are also crucial to elucidate the effects of substrate variation on proliferation and morphology of those 
terminally differentiated cells. For example, a body of evidence indicates that cell adhesion depends on substrate stiffness $[28,52,53]$, which is closely related with cell proliferation. Proliferation of human corneal keratocytes is found to increase with ridge width, from 0.35 to $10 \mu \mathrm{m}$, of grooved chitosan or PDMS substrate, but is comparable to that on the unpatterned control, which is in accordance with our observation that dimension is more important than topography (right panel in Fig. 2e) [54]. Altering the inter-pillar gap size reveals dramatic changes in fibroblast proliferation and identifies remarkable stress-induced variations in cytoskeleton and focal adhesion morphology [55]. A few studies have been focusing on the combinatory effect of stiffness and dimension on topographical substrates. Stiff and topographical PA substrates favor the alignment (circularity) of rat cardiac fibroblasts [52], similar to our observation in the rBMSC spreading (Fig. 3). A ridge width of $10 \mu \mathrm{m}$ with dimensions of the cells' own size, but not the smaller $(5 \mu \mathrm{m})$ or larger $(20,25$, or $50 \mu \mathrm{m}$ ) size, is favorable for L929 fibroblasts to adhere and spread on a grooved, poly(ethylene glycol)-based hydrogel, whereas the effect of varied stiffness $(91,350$, or $1100 \mathrm{kPa})$ was only manifested in combination with topography to foster the adhesion and spreading on softer substrates [56], findings that are consistent with our observations on evenly dimensioned, stiff and soft substrates (Fig. 3c-d). Human osteosarcoma SaOs-2 and MG63 cells placed on a square pillar PDMS substrate spread specifically by pushing (or pulling) down their nuclei and main bodies into the grooves between pillars [57], a finding that is similar to our findings that rBMSCs tend to be located on the wider site at a cell-typespecific threshold of dimension (Fig. S4). Thus, not only did our data support, in principle, the previous observations, but they also added additional information regarding the impact of varied topography.

It should be noted that the depth of a pitch or a groove is also an important factor, which is not considered in the current work. For example, the morphology and orientation of rat cardiomyocytes were found to be influenced mainly by the depth ( 100 or $350 \mathrm{~nm}$ ) of the grooved polystyrene and polyurethane substrate, whereas the contractile function of the cells was regulated by the coupled effect of depth and stiffness [58]. The spreading of MG63 osteoblast-like cells was reduced, and cell elongation was enhanced, when increasing the titania pillar height from 15 to $100 \mathrm{~nm}$ [59]. Integrating the information of depth dimension into the combinatory effect would result in the bifurcating observation. The dimension (depth) and stiffness were found to highly co-regulate the spreading of human umbilical vein endothelial cells on round pillars of silica or PDMS [60] or the spreading of bovine aortic endothelial cells on grooves of PA [53], whereas our data indicated that topography is more predominant than stiffness and dimension (width) in rBMSC spreading (area). Another example is that the rat Schwann cell precursor line is most likely aligned in the narrowest and deepest grooves and differentiate toward early Schwann cells on stiffer, narrower grooves [44], whereas the main body of evidence $[5,46,47,51,61,62]$, including ours here, support that MSCs are in favor of a soft substrate to differentiate into neuronal cells. Thus, caution should be taken when the predominance of regulating factors is applied into other types and/or dimensions of topographical substrates because the importance of each regulating factor depends on the cell types, material properties, as well as mechanotransductive signaling, which will be investigated in future studies.

\section{Conclusions}

While the topographically induced fate decision of rBMSCs is used to mimic in vitro their responses in the physiologically 3D niche, their sensitivity and capacity to undergo cell spreading is dramatically improved via various changes in stiffness, topography, and dimension. The mechanism underlying this difference involves their differential ability to alter the proliferation, morphology, and differentiation independently. Interestingly, the seemingly combinatory effect of topography and dimension was also found in regulating vimentin re-organization. These results imply the differential predominance of mechano-biological responses for rBMSCs, particularly when they are considered a therapeutic cell source for regenerative application.

\section{Acknowledgments}

The authors thank to Dr. Yan Zhang for technical assistance. This work was supported by National Natural Science Foundation of China grant 31110103918, National Key Basic Research Foundation of China grant 2011CB710904, Strategic Priority Research Program grant XDA01030102, and National High Technology Research and Development Program of China grant 2011AA020109.

\section{Appendix A. Supplementary data}

Supplementary data related to this article can be found at http:// dx.doi.org/10.1016/j.biomaterials.2013.06.059.

\section{References}

[1] Schofield R. Relationship between spleen solony-forming cell and hematopoietic stem-cell-hypothesis. Blood Cells 1978;4:7-25.

[2] McAdams TA, Miller WM, Papoutsakis ET. Lineage distribution of ex vivo hematopoietic cultures is substantially influenced by small changes in culture pH. Blood 1996;88:2416.

[3] Guthridge MA, Barry EF, Felquer FA, McClure BJ, Stomski FC, Ramshaw H, et al The phosphoserine-585-dependent pathway of the GM-CSF/IL-3/IL-5 receptors mediates hematopoietic cell survival through activation of NF-kappa B and induction of bcl-2. Blood 2004;103:820-7.

[4] Wei Q, Clarke L, Qian B, Zhang C, Shannon P, Gutmann D, et al. Astrocytespecific PTEN deletion results in developmental abnormalities of the central nervous system. Neuro-Oncology 2004;6:349.

[5] Engler AJ, Sen S, Sweeney HL, Discher DE. Matrix elasticity directs stem cell lineage specification. Cell 2006;126:677-89.

[6] Witkowska-Zimny M, Walenko K, Walkiewicz AE, Pojda Z, Przybylski J, Lewandowska-Szumiel M. Effect of substrate stiffness on differentiation of umbilical cord stem cells. Acta Biochim Pol 2012;59:261-4.

[7] Her GJ, Wu HC, Chen MH, Chen MY, Chang SC, Wang TW. Control of threedimensional substrate stiffness to manipulate mesenchymal stem cell fate toward neuronal or glial lineages. Acta Biomater 2013;9:5170-80.

[8] Katoh M. WNT signaling in stem cell biology and regenerative medicine. Curr Drug Targets 2008;9:565-70.

[9] Ling L, Nurcombe V, Cool SM. Wnt signaling controls the fate of mesenchymal stem cells. Gene 2009;433:1-7.

[10] Takada I, Kouzmenko AP, Kato S. Wnt and PPAR gamma signaling in osteoblastogenesis and adipogenesis. Nat Rev Rheumatol 2009;5:442-7.

[11] Galli C, Passeri G, Ravanetti F, Elezi E, Pedrazzoni M, Macaluso GM. Rough surface topography enhances the activation of Wnt/beta-catenin signaling in mesenchymal cells. J Biomed Mater Res Part A 2010;95A:682-90.

[12] Luther G, Wagner ER, Zhu GH, Kang O Luo O Lamplot J, et al. BMP-9 induced osteogenic differentiation of mesenchymal stem cells: molecular mechanism and therapeutic potential. Curr Gene Ther 2011;11:229-40.

[13] Rowlands AS, George PA, Cooper-White JJ. Directing osteogenic and myogenic differentiation of MSCs: interplay of stiffness and adhesive ligand presentation. Am J Physiol-Cell Ph 2008;295:C1037-44.

[14] Seo CH, Furukawa K, Montagne K, Jeong H, Ushida T. The effect of substrate microtopography on focal adhesion maturation and actin organization via the RhoA/ROCK pathway. Biomaterials 2011;32:9568-75.

[15] Trappmann B, Gautrot JE, Connelly JT, Strange DGT, Li Y, Oyen ML, et al. Extracellular-matrix tethering regulates stem-cell fate. Nat Mater 2012;11: 642-9.

[16] Shih YRV, Tseng KF, Lai HY, Lin CH, Lee OK. Matrix stiffness regulation of integrin-mediated mechanotransduction during osteogenic differentiation of human mesenchymal stem cells. J Bone Miner Res 2011;26:730-8.

[17] Zou C, Luo Q, Qin J, Shi Y, Yang L, Ju B, et al. Osteopontin promotes mesenchymal stem cell migration and lessens cell stiffness via integrin beta1, FAK, and ERK pathways. Cell Biochem Biophys 2013;65:455-62. 
[18] Brydone AS, Dalby MJ, Berry CC, Meek RMD, McNamara LE. Grooved surface topography alters matrix-metalloproteinase production by human fibroblasts. Biomed Mater 2011;6:1-9.

[19] Pek YS, Wan AC, Ying JY. The effect of matrix stiffness on mesenchymal stem cell differentiation in a 3D thixotropic gel. Biomaterials 2010;31:385-91.

[20] Burke DP, Kelly DJ. Substrate stiffness and oxygen as regulators of stem cell differentiation during skeletal tissue regeneration: a mechanobiological model. PLoS One 2012;7:1-12.

[21] Tse JR, Engler AJ. Stiffness gradients mimicking in vivo tissue variation regulate mesenchymal stem cell fate. PLoS One 2011;6:1-9.

[22] Wang Y, Wang GX, Luo XD, Qiu JH, Tang CJ. Substrate stiffness regulates the proliferation, migration, and differentiation of epidermal cells. Burns 2012;38: 414-20.

[23] Witkowska-Zimny M, Walenko K, Wrobel E, Mrowka P, Mikulska A, Przybylski J. Effect of substrate stiffness on the osteogenic differentiation of bone marrow stem cells and bone-derived cells. Cell Biol Int 2013. http:// dx.doi.org/10.1002/cbin.10078.

[24] Watari S, Hayashi K, Wood JA, Russell P, Nealey PF, Murphy CJ, et al. Modulation of osteogenic differentiation in hMSCs cells by submicron topographically-patterned ridges and grooves. Biomaterials 2012;33:128-36.

[25] Gobaa S, Hoehnel S, Roccio M, Negro A, Kobel S, Lutolf MP. Artificial niche microarrays for probing single stem cell fate in high throughput. Nat Methods 2011;8:949-55.

[26] Poellmann MJ, Harrell PA, King WP, Johnson AJW. Geometric microenvironment directs cell morphology on topographically patterned hydrogel substrates. Acta Biomaterialia 2010;6:3514-23.

[27] Seo CH, Furukawa K, Suzuki Y, Kasagi N, Ichiki T, Ushida T. A topographically optimized substrate with well-ordered lattice micropatterns for enhancing the osteogenic differentiation of murine mesenchymal stem cells. Macromol Biosci 2011;11:938-45.

[28] Aydin D, Louban I, Perschmann N, Blummel J, Lohmuller T, CavalcantiAdam EA, et al. Polymeric substrates with tunable elasticity and nanoscopically controlled biomolecule presentation. Langmuir 2010;26:15472-80.

[29] Teo BKK, Goh SH, Kustandi TS, Loh WW, Low HY, Yim EKF. The effect of micro and nanotopography on endocytosis in drug and gene delivery systems. Biomaterials 2011;32:9866-75.

[30] Unadkat HV, Hulsman M, Cornelissen K, Papenburg BJ, Truckenmuller RK, Post GF, et al. An algorithm-based topographical biomaterials library to instruct cell fate. Proc Natl Acad Sci U S A 2011;108:16565-70.

[31] Park J, Bauer S, Pittrof A, Killian MS, Schmuki P, von der Mark K. Synergistic control of mesenchymal stem cell differentiation by nanoscale surface geometry and immobilized growth factors on $\mathrm{TiO}_{2}$ nanotubes. Small 2012;8: 98-107.

[32] Wang HJ, Cao Y, Sun YY, Wang K, Cao C, Yang L, et al. Is there an optima topographical surface in nanoscale affecting protein adsorption and cell behaviors? J Nanopart Res 2011;13:4201-10.

[33] Lee MH, Oh N, Lee SW, Kang JH, Lee SC, Leesungbok R. Enhancement of dynamic wettability, cell adhesion, and alkaline phosphatase activity of primary cells on titanium substrata with combined surface topographies of microgrooves and acid-etched roughness. Tissue Eng Regen Med 2010;7:501-12.

[34] Cheng X, Guo LJ. One-step lithography for various size patterns with a hybrid mask-mold. Microelectron Eng 2004;71:288-93.

[35] Engler AJ. Mechanical derivation of functional myotubes from adiposederived stem cells. J Tissue Eng Regen M 2012;6:2482-91.

[36] Dado D, Sagi M, Levenberg S, Zemel A. Mechanical control of stem cell differentiation. Regen Med 2012;7:101-16.

[37] Cohen DM, Chen CS. Mechanical control of stem cell differentiation. In: Bhatia S, Polak J, editors. StemBook. The stem cell research community. Boston: StemBook; 2008. p. 1-16.

[38] Kilian KA, Bugarija B, Lahn BT, Mrksich M. Geometric cues for directing the differentiation of mesenchymal stem cells. Proc Natl Acad Sci U S A 2010;107: 4872-7.

[39] Evans ND, Minelli C, Gentleman E, LaPointe V, Patankar SN, Kallivretaki M et al. Substrate stiffness affects early differentiation events in embryonic stem cells. Eur Cells Mater 2009;18:1-14.

[40] Wang LS, Boulaire J, Chan PPY, Chung JE, Kurisawa M. The role of stiffness of gelatin-hydroxyphenylpropionic acid hydrogels formed by enzyme-mediated crosslinking on the differentiation of human mesenchymal stem cell. Biomaterials 2010;31:8608-16.

[41] Leipzig ND, Shoichet MS. The effect of substrate stiffness on adult neural stem cell behavior. Biomaterials 2009;30:6867-78.

[42] Wood JA, Ly I, Borjesson DL, Nealey PF, Russell P, Murphy CJ. The modulation of canine mesenchymal stem cells by nano-topographic cues. Exp Cell Res 2012;318:2438-45.

[43] Yang JL, Liu AM, Zhou CR. Proliferation of mesenchymal stem cell on chitosan films associated with convex micro-topography. J Biomat Sci-Polym E 2011;22:919-29.

[44] Cai L, Zhang L, Dong JY, Wang SF. Photocured biodegradable polymer substrates of varying stiffness and microgroove dimensions for promoting nerve cell guidance and differentiation. Langmuir 2012;28:12557-68.

[45] Zhu HB, Cao BR, Zhen ZP, Laxmi AA, Li D, Liu SR, et al. Controlled growth and differentiation of MSCs on grooved films assembled from monodisperse biological nanofibers with genetically tunable surface chemistries. Biomaterials 2011;32:4744-52.

[46] Lee MR, Kwon KW, Jung H, Kim HN, Suh KY, Kim K, et al. Direct differentiation of human embryonic stem cells into selective neurons on nanoscale ridge groove pattern arrays. Biomaterials 2010;31:4360-6.

[47] Sorensen A, Alekseeva T, Katechia K, Robertson M, Riehle MO, Barnett SC. Long-term neurite orientation on astrocyte monolayers aligned by microtopography. Biomaterials 2007;28:5498-508.

[48] Le DM, Kulangara K, Adler AF, Leong KW, Ashby VS. Dynamic topographical control of mesenchymal stem cells by culture on responsive poly(epsiloncaprolactone) surfaces. Adv Mater 2011;23:3278-83.

[49] Kim EJ, Boehm CA, Mata A, Fleischman AJ, Muschler GF, Roy S. Post microtextures accelerate cell proliferation and osteogenesis. Acta Biomaterialia 2010;6:160-9.

[50] Hoffman-Kim D, Mitchel JA, Bellamkonda RV. Topography, cell response, and nerve regeneration. Annu Rev Biomed Eng 2010;12:203-31.

[51] D’Angelo F, Armentano I, Mattioli S, Crispoltoni L, Tiribuzi R, Cerulli GG, et al. Micropatterned hydrogenated amorphous carbon guides mesenchymal stem cells towards neuronal differentiation. Eur Cells Mater 2010;20:231-44.

[52] Al-Haque S, Miklas JW, Feric N, Chiu LLY, Chen WLK, Simmons CA, et al. Hydrogel substrate stiffness and topography interact to induce contact guidance in cardiac fibroblasts. Macromol Biosci 2012;12:1342-53.

[53] Charest JM, Califano JP, Carey SP, Reinhart-King CA. Fabrication of substrates with defined mechanical properties and topographical features for the study of cell migration. Macromol Biosci 2012;12:12-20.

[54] Koo S, Ahn SJ, Zhang H, Wang JC, Yim EKF. Human corneal keratocyte response to micro- and nano-gratings on chitosan and PDMS. Cell Mol Bioeng 2011;4:399-410.

[55] Kolind K, Dolatshahi-Pirouz A, Lovmand J, Pedersen FS, Foss M, Besenbacher F A combinatorial screening of human fibroblast responses on micro-structured surfaces. Biomaterials 2010;31:9182-91.

[56] Schulte VA, Diez M, Hu Y, Moeller M, Lensen MC. Combined influence of substrate stiffness and surface topography on the antiadhesive properties of Acr-sP(EO-stat-PO) hydrogels. Biomacromolecules 2010;11:3375-83.

[57] Badique F, Stamov DR, Davidson PM, Veuillet M, Reiter G, Freund JN, et al. Directing nuclear deformation on micropillared surfaces by substrate geometry and cytoskeleton organization. Biomaterials 2013;34:2991-3001.

[58] Wang PY, Yu JS, Lin JH, Tsai WB. Modulation of alignment, elongation and contraction of cardiomyocytes through a combination of nanotopography and rigidity of substrates. Acta Biomaterialia 2011;7:3285-93.

[59] Sjostrom T, Lalev G, Mansell JP, Su B. Initial attachment and spreading of MG63 cells on nanopatterned titanium surfaces via through-mask anodization. Appl Surf Sci 2011;257:4552-8.

[60] Dickinson LE, Rand DR, Tsao J, Eberle W, Gerecht S. Endothelial cell responses to micropillar substrates of varying dimensions and stiffness. J Biomed Mater Res Part A 2012;100A:1457-66.

[61] Recknor JB, Sakaguchi DS, Mallapragada SK. Directed growth and selective differentiation of neural progenitor cells on micropatterned polymer substrates. Biomaterials 2006;27:4098-108.

[62] Migliorini E, Grenci G, Ban J, Pozzato A, Tormen M, Lazzarino M, et al. Acceleration of neuronal precursors differentiation induced by substrate nanotopography. Biotechnol Bioeng 2011;108:2736-46. 